\title{
Violent behaviour in early psychosis patients: can we identify clinical risk profiles? Clinical risk profiles in early psychosis patients
}

Valerie. Moulin, Maitre de Conferences, Unit for research in legal psychiatry and psychology, Institute of Forensic Psychiatry, Department of psychiatry, Lausanne University Hospital (CHUV), Lausanne, Switzerland: Valerie.Moulin@chuv.ch

Julie. Palix, Doctor, Unit for research in legal psychiatry and psychology, Institute of Forensic Psychiatry, Department of psychiatry, Lausanne University Hospital (CHUV), Lausanne, Switzerland: Julie.Palix@chuv.ch

Philippe. Golay, Doctor, Service of General Psychiatry, Department of Psychiatry, Lausanne University Hospital (CHUV), Lausanne, Switzerland : Philippe.Golay@chuv.ch Alexandre Dumais, Doctor, Institut Philippe-Pinel de Montréal, 10905, Montréal (Québec), Canada : alexandredumais@hotmail.com

M. Mehdi Gholamrezaee, Statistician, Centre for Psychiatric Epidemiology and Psychopathology, Department of Psychiatry, Lausanne University Hospital (CHUV), Lausanne, Switzerland: Mehdi.Gholam@chuv.ch

Agathe. Azzola, Psychologist, Unit for research in legal psychiatry and psychology, Institute of Forensic Psychiatry, Department of psychiatry, Lausanne University Hospital (CHUV), Lausanne, Switzerland: azzola.agathe@gmail.com

Philipp.S. Baumann, Psychiatrist, Service of General Psychiatry, Department of Psychiatry, Lausanne University Hospital (CHUV), Lausanne, Switzerland: Philipp.Baumann@chuv.ch Luis. Alameda, Psychiatrist, Service of General Psychiatry, Department of Psychiatry, Lausanne University Hospital (CHUV), Lausanne, Switzerland : Luis.AlamedaFernandez@.chuv.ch

Philippe. Conus, Professor, Service of General Psychiatry, Department of Psychiatry, Lausanne University Hospital (CHUV), Lausanne, Switzerland : Philippe.Conus@chuv.ch Corresponding author: Valerie. Moulin, Maitre de Conferences, Unit for research in legal psychiatry and psychology, Institute of Forensic Psychiatry, Department of psychiatry,

This is the author manuscript accepted for publication and has undergone full peer review but has not been through the copyediting, typesetting, pagination and proofreading process, which may lead to differences between this version and the Version of Record. Please cite this article as doi: 10.1111/eip.12512

This article is protected by copyright. All rights reserved. 
Lausanne University Hospital (CHUV), Site de Cery, Bat. Les Cèdres, 1008 Prilly, Lausanne, Switzerland:

Tel : +41(0)213143021; Fax : +41(0)216436469

Valerie.Moulin@chuv.ch

\section{Acknowledgements}

This work was supported by National Center of Competence in Research (NCCR) "SYNAPSY - The Synaptic Bases of Mental Diseases" (project number 33), in the collection and analysis of the data. P.S.B. is financially supported by Leenaards Foundation.

This article is protected by copyright. All rights reserved. 
Violent behaviour in early psychosis patients: can we identify clinical risk profiles?

Clinical risk profiles in early psychosis patients

This article is protected by copyright. All rights reserved. 


\begin{abstract}
Aims: The objective of this study is to explore, within a sample of early psychosis patients (EPP), if subgroups regarding rate of violent behaviour (VB) against others can be identified on the basis of dynamic risk factors (treatment modifiable characteristics).
\end{abstract}

Methods: In a sample of 265 EPP, treated at the Treatment and Early Intervention in Psychosis Program in Lausanne, we conducted a latent-class analysis on the basis of the main dynamic VB risk factors (substance use disorder, positive symptoms, insight, and impulsivity). VB were restricted to "serious violence" and were assessed through patients self-report, interview with relatives or forensic services and with a standardized instrument.

Results: The analysis confirmed the heterogeneity of the sample regarding rate of VB. Patients could be stratified within 4 subgroups, 3 of which were at increased risk of VB. The two groups with the highest rates of VB displayed specific clinical profiles. The first one was characterised by high levels of impulsivity, hostility, positive symptoms and substance use disorder, and the second, by low level of insight and low social functioning. These patterns suggest that significant difficulties in social interaction may contribute to the emergence of aggressive reactions against others.

Conclusions: Identification of EPP at increased risk of VB seems possible on the basis of dynamic risk factors. If confirmed prospectively, this could pave the way to the development of preventive strategies and specific interventions. 
Key words: Early psychosis, impulsivity, violent behaviour, schizophrenia.

\section{INTRODUCTION}

While the vast majority of patients with schizophrenia are not violent, a significant number of studies have shown that they have nevertheless a higher risk to display violent behavior (VB) than the general population (Fazel, Långström, Hjern, Grann, \& Lichtenstein, 2009; Hodgins, 2010; Large \& Nielssen, 2011; Ouzir, 2013; Silverstein, Del Pozzo, Roché, Boyle, \& Miskimen, 2015). Various studies have shown that this is already true in the early phase of psychotic disorders (Hodgins et al., 2011; Langeveld et al., 2014; Large \& Nielssen, 2011; Nielssen, Malhi, McGorry, \& Large, 2012; Winsper et al., 2013). In the literature, there is an emerging consensus that the group of schizophrenia patients displaying VB is not homogeneous and that it is rather composed of different subgroups where a range of psychopathological and clinical characteristics contribute to the emergence of such behaviors (Bo et al., 2013; Dumais et al., 2011; Joyal, Côté, Meloche, \& Hodgins, 2011; Joyal, Dubreucq, Gendron, \& Millaud, 2007). Furthermore, it has been suggested that research in this domain should not only aim at refining our understanding of psychopathological mechanisms leading to VB but also at identifying patient profiles based on "dynamic" risk factors of VB (Coid et al., 2013; Douglas, Guy, \& Hart, 2009; Dumais et al., 2011; Hodgins, 2010; Joyal et al., 2007), i.e. factors susceptible to evolve with treatment (such as substance abuse or certain types of symptoms), as opposed to "static risk factors" (such as gender or past aggression) which can't be modified (Webster, Douglas, Eaves, \& Hart, 1997). Unfortunately, very little research has been conducted on this topic in early psychosis patients (EPP) despite its potential usefulness in adapting treatment and developing specific early preventive strategies (Douglas \& Skeem, 2005; Hodgins et 
al., 2011; Large, Dall, \& Nielssen, 2014; Large \& Nielssen, 2011; Witt, Van Dorn, \& Fazel, 2013). The literature has shown that among patients with schizophrenia and first episode psychosis (FEP), the presence of isolated dynamic risk factors such as substance abuse or dependency (Fazel et al., 2009; Large, 2014; Latalova, 2014; Vacheron \& Cornic, 2010), antisocial personality disorders (Putkonen, Kotilainen, Joyal, \& Tiihonen, 2004) or positive psychotic symptoms (Elbogen \& Johnson, 2009; Lincoln, Lüllmann, \& Rief, 2007; Nolan et al., 2005; Swanson et al., 2006; Witt, Lichtenstein, \& Fazel, 2015) increases the risk of VB. More recently, several studies have shown that lack of insight (Bjørkly, 2006; Foley et al., 2005; Reinharth, Reynolds, Dill, \& Serper, 2014; Verma, Poon, Subramaniam, \& Chong, 2005; Voyer, Jaafari, \& Senon, 2011) and the presence of impulsivity (Bjørkly, 2013) could also play a critical role in the risk of VB in schizophrenia and FEP (Bjørkly, 2013; Nielssen et al., 2012; Silverstein et al., 2015; Volavka \& Citrome, 2008; Witt et al., 2013). In addition, various studies have shown that the levels of these factors may differ among subgroups of violent patients with chronic schizophrenia and a range of psychopathological profiles have been identified on this basis. The first one is composed of patients with a diagnosis of paranoid schizophrenia with predominant positive symptoms, where VB can be influenced by the content of symptoms [ex. delusions of persecution (Dubreucq, Joyal, \& Millaud, 2005; Joyal et al., 2011; Joyal, Putkonen, Paavola, \& Tiihonen, 2004; Volavka \& Citrome, 2008)] and where violent acts are often planned, less impulsive and directed against a family member. A second profile consists of patients with a diagnosis of schizophrenia associated with comorbid substance use disorder (SUD) and antisocial personality disorder (APD) (Bo et al., 2013; Grann, Danesh, \& Fazel, 2008) where VB would derive from the association of APD and drug use (Joyal et al., 2007). Recent studies have proposed a third profile, characterised by the combination of a high level of impulsivity (Bo et al., 
2013; Dumais et al., 2011; Enticott, Ogloff, \& Bradshaw, 2008; Volavka \& Citrome, 2008) and SUD. Unfortunately, very little is known in this regard for EPP. Considering the major impact VB can have both on victims and patients themselves, further research seems urgent in order to advance this neglected field. Focusing on the identification of clinical profiles based on dynamic risk factors may indeed pave the way to the development of specific preventive strategies which are currently not available.

Considering these elements, we decided to conduct a study in a sample of EPP, with the objective to explore if subgroups regarding rate of VB could be identified on the basis of dynamic risk factors.

\section{METHODS}

\section{Procedure and participants}

Patients were recruited at the Treatment and early Intervention in Psychosis Program (TIPP), a specialized early psychosis program, implemented at the Department of Psychiatry CHUV, in Lausanne, Switzerland (Baumann et al., 2013; Conus \& Bonsack, 2004). Entry criteria to the program are: (i) age 18 to 35 years; (ii) residence in the catchment area; (iii) meeting threshold criteria for psychosis, as defined by the 'Psychosis threshold' subscale of the Comprehensive Assessment of At Risk Mental States Scale (Yung et al., 2005). Exclusion criteria are (i) antipsychotic medication for more than a total of 6 months, (ii) psychosis related to intoxication or organic brain disease, or (iii) an intelligence quotient $<70$. The Research and Ethics Committee of the Faculty of Biology and Medicine of Lausanne University granted access to TIPP clinical data for research purposes.

At the time of this study, 265 patients had been followed-up prospectively over 36 months, and they were dichotomised based on the presence or not of VB. The group of patients with VB had 
committed physical aggression against people at least once, either before entering into the program and/or during the program, meeting definition of "serious violence" i.e. "as assault causing any degree of injury, any use of a weapon or any sexual assault. The term any was used when the severity of the violence was not specified" (Large \& Nielssen, 2011).

\section{Measures}

\section{$\underline{\text { Premorbid factors }}$}

Past psychiatric diagnoses were assessed according to Diagnostic and Statistical Manual of Mental Disorders (APA, 2000) criteria. Past history of trauma was assessed on the basis of the knowledge of history of patients in the frame of a 3 year's trusting relationship, and based on interviews with relatives when indicated (Alameda et al., 2015). Patients were considered as having been exposed to trauma if they had faced at least one experience of sexual or physical abuse (Varese et al., 2012).

\section{$\underline{\text { Diagnostic assessment }}$}

Diagnosis is the result of an expert consensus and based on the following elements: (1) Diagnosis reported by a treating psychiatrist in all medical documents and at the end of any hospitalization; (2) Longitudinal assessment by case managers $(\mathrm{CM})$ over the 3 years of treatment. The consensus diagnostic procedure is carried out after 18 months in treatment by a psychiatrist and the psychologist who is in charge of assessments over the treatment period, and is based on DSM-IV criteria (APA, 2000). Main diagnoses were sub-divided into 3 classes: paranoid schizophrenia, nonparanoid schizophrenia and other psychotic disorders. 
Dynamic factors: Positive symptoms, substance use disorder, insight and impulsivity.

All of the dynamic factors were evaluated at program entry. The level of symptoms was measured using the positive subscale of the Positive and Negative Syndrome Scale (PANSS) (Kay, Flszbein, \& Opfer, 1987). Impulsivity was assessed by the addition of 2 PANSS items: "poor impulse control" and "difficulty in delaying gratification" which correspond to the consensual definition of impulsivity proposed by Moeller et al. (Moeller, Barratt, Dougherty, Schmitz, \& Swann, 2001). We selected these items to assess the main dimensions of impulsivity because our specialized impulsivity scale could not be administered to the whole cohort. Substance use disorder (SUD) at baseline was assessed in 2 ways: first, on the basis of DSM-IV criteria (APA, 2000) and second, SUD was dichotomized between "absent/light substance use" and "moderate to severe substance use" on the basis of the CM rating Scale (Drake et al., 1990). The level of insight was rated, using a 3-point scale: absent, partial and full. Full insight meant awareness of the illness and the necessity of treatment.

Other factors: general functioning and other aspects of psychopathology

The functional level at program entry was evaluated using two scales : the Social and Occupational Functioning Assessment Scale (SOFAS) (Morosini, Magliano, Brambilla, Ugolini, \& Pioli, 2000) and the Global Assessment of Functioning (GAF) (Goldman, Skodol, \& Lave, 1992). While SOFAS only takes the social and occupational functioning into account, GAF also includes the intensity of symptoms. Negative symptoms, general psychopathology and PANSS risk were assessed with the PANSS scale.

$\underline{\text { Identification of episodes of VB }}$

This article is protected by copyright. All rights reserved. 
Episodes of VB were identified by three distinct ways: firstly, by CMs on the basis of questionnaire completed for all patients [listing violent offenses (Swiss Criminal Code) and VB (such as assault and battery)] in the frame of the clinical interactions occurring between them and patients over the entire 36 month treatment period (averaging 100 contacts per patients). The meta-analysis of Winsper et al. (Winsper et al., 2013) showed good reliability and validity in the self-reporting of serious aggression rate. Secondly, CMs gathered additional information through contact with parents, significant others and the forensic psychiatric services (hetero-reporting of aggression). Finally, episodes of VB occurring during the treatment phase were identified on the basis of the Staff Observation Aggression Scale [SOAS-R scale (Nijman et al., 1999), a structured assessment tool], which lists all critical events related to a VB during hospitalisations.

\section{Statistical analysis}

To assess the existence of specific patients' subgroups, a latent class analysis (LCA) was conducted on the following factors: SUD (presence or absence), impulsivity, insight level, positive symptoms level, and main psychosis diagnosis ( 3 groups). Although diagnosis can be considered as a more stable factor than the others, it may also change in EPP, which is why we included it in the analysis. To determine the best number of classes we relied upon the BIC (Bayesian Information Criterion) coefficient (Schwarz, 1978). The BIC balances model fit with its complexity (number of parameters). For the sake of parsimony, it was further verified whether a solution with one less class could present a similar degree of adjustment. In this regard, a Lo-Mendell-Rubin Adjusted Likelihood Ratio Test and a Parametric Bootstrapped Likelihood Ratio Test were performed. The LCA was performed with the Mplus statistical package version 7.3. To determine the specific 
characteristics of each class, we used the Cramer's V test or T test. A significant p-value indicates that a variable provides between class discrimination. Finally the classes were compared on a set of variables that were not used to develop the profiles (demographic data, presence of a past history of treatment for a non-psychotic disorder, negative and general domain of the PANSS scale, functioning assessment and VB - table2).

\section{RESULTS}

\section{Sample characteristics.}

Among the 265 patients included in the study, 72 displayed VB that involved a person (27.2\%) and $15(5.7 \%)$ committed victimless crimes. The latter were excluded from the study considering they could neither be considered as controls nor as violent patients. The analysis was therefore conducted in a sample of 250 patients. Among the 72 patients, 10 displayed VB only prior to enter the program, and, 62 during the program. Other characteristics are outlined in Table 1 and Table 2.

\section{Identification of subgroups of patients with VB on the basis of the main dynamic risk factors}

Models with an increasing number of classes were estimated. The four-class solution was selected on the basis of its lowest BIC value and clinical interpretability. Solutions including a higher number of classes were discarded because they were unstable (the best log-likelihood value was not replicated) and untrustworthy because of model under-identification. The Lo-Mendell-Rubin Adjusted Likelihood Ratio Test $(\mathrm{p}=.012)$ and the Parametric Bootstrapped Likelihood Ratio Test $(\mathrm{p}<.001)$ confirmed that the four class solution was to be preferred to a solution including one lessclass. This analysis allowed the stratification of the sample within 4 patient's subgroups. Sub-group 
1 was the largest and contained a majority of non-violent patients (84\%) with diagnoses of nonparanoid schizophrenia or other psychotic disorders and globally lower levels of dynamic risk factors. Subgroup 2 was composed of patients with heterogeneous psychosis diagnoses, low level of insight and a $41 \%$ prevalence of VB. Subgroup 3 was composed of patients almost exclusively diagnosed with paranoid schizophrenia (96\%) with low levels of impulsivity and positive symptoms and higher level of insight compared to classes 2 and $4 ; 40 \%$ of them had displayed VB. Subgroup 4 was the smallest group in the cohort $(\mathrm{N}=16 ; 6.4 \%)$ and had the highest prevalence of violent patients (62\%). Most patients within this subgroup had non-paranoid schizophrenia (59\%), high levels of SUD, impulsivity, and positive symptoms, and a low level of insight. In this analysis SUD explained $2.7 \%$ of the variance between subgroups, insight $6 \%$, positive symptoms $23 \%$, diagnosis $40.4 \%$ and impulsivity $90 \%$.

\section{$\underline{\text { Table } 1}$}

\section{Specific subgroup characteristics}

Patients in subgroup 1 had a better level of functioning $(E G F=53.8$, SOFAS $=56.3)$ and lower general subscale (31.8) and total (62.4) score on the PANSS than the other groups. In subgroup 2, 76\% had psychiatric treatment before entering TIPP (for non-psychotic diagnosis). Subjects had an overall level of functioning that was impaired $(\mathrm{EGF}=45.5$, SOFAS=47.9). In subgroup 3, patients had moderate functional impairment $(\mathrm{EGF}=49.2$, SOFAS=51.4). Subgroup 4 was composed of a higher percentage of females patients compared to the three other groups, the vast majority $(75 \%)$ had been exposed to significant trauma and they also had a significant degree of functional impairment. Other characteristics are outlined in Table 2. 


\section{Table 2}

\section{DISCUSSION}

To our knowledge, this is the first study attempting to identify EPP at higher risk of VB on the basis of dynamic risk factors. This topic is of importance considering it may pave the way to the development of strategies to prevent such events to occur. Our main finding is that it is indeed possible to identify subgroups of patients at increased risk to display VB on the basis of clinical characteristics that may be amenable to treatment.

Overall, within our sample, $27 \%$ of patients had displayed VB at least once, a rate which is slightly higher than what has been reported in previous meta-analyses (Large \& Nielssen, 2011; Winsper et al., 2013). However, variations regarding duration of follow-up and definition of VB may explain these differences and limit the validity of comparison between studies (Large \& Nielssen, 2011; Winsper et al., 2013). Nevertheless, this high rate of VB confirms the importance to identify subgroups of patients at increased risk to display such behaviors and to identify factors that may be targeted by treatment in order to develop preventive approaches.

Our study allowed the identification of 3 subgroups of patient with an increased rate of VB. A small number of patients (subgroup 4 in our analyses) displayed high rate of VB (62\%), and repetitive aggressions [with relatively low severity (Dumais et al., 2011)]. These were patients with nonparanoid schizophrenia, high rate of SUD, as well as high levels of impulsivity and positive symptoms. The observation that a high percentage of patients from this subgroup had been exposed to traumatic events ( $75 \%$ of this subgroup) suggests that their impulsivity and lack of control may be linked to an emotion-regulation deficit that may result from such events (Aebi et al., 2017; Negrao, 
Bonanno, Noll, Putnam, \& Trickett, 2005). In addition, the high prevalence of substance use (mainly represented by marijuana and alcohol) may also have acted as a facilitator in the emergence of aggression. Further, the high level of hostility and other positive symptoms they displayed during the acute phase may have contributed to the emergence of VB after the onset of psychosis (Lapworth et al., 2009). These characteristics, coupled to the observation that, in $40 \%$ of cases, VB start before entry into the program and continued during treatment, suggests this subgroup may overlap with the “Early-starter offender” described by Hodgins (Hodgins, 2008, 2010). Entry into delinquency in this subgroup could in fact follow a pathway that is similar to the one followed by non-psychotic offenders and may be driven mainly by the conjunction of high impulsivity and substance abuse. It could however worsen with the emergence of psychosis, especially with the occurrence of positive symptoms. In another study we have shown indeed that the impact of impulsivity on the probability of VB was potentiated when associated with a low level of insight and a high level of positive symptoms (Moulin et al., Submitted).

A second subgroup (subgroup 2) is characterized by low level of insight and functioning. This combination can potentially lead to significant difficulties in social interaction, and hence to the emergence of aggressive reactions against others, in a pattern where poor interpersonal skills, combined with lack of insight lead to aggressive interactions. These findings could explain the conflicting results of the literature (Bjørkly, 2006; Bonnet, Lacambre, Schandrin, Capdevielle, \& Courtet, 2017; Voyer et al., 2011) about the role of insight (in schizophrenia and FEP) on VB: lack of insight could play an indirect role in its links with VB (Moulin et al., 2017) by increasing the difficulties in social functioning. 
A third subgroup with high rate of VB, is composed of patients with paranoid schizophrenia and low level of impulsivity: it corresponds to the classical profile of potentially violent patients described in the literature (Dubreucq et al., 2005; Joyal et al., 2007), whose VB are more likely to be planed (Silverstein et al., 2015) and to lead to penal consequences.

Our results suggest that the two first subgroups described above may be specific to EPP and that various preventive strategies could be developed on this basis. : firstly, a high-risk group of VB with high impulsivity and SUD, that could be potentiated by positive symptoms and lack of insight during this period. In line with Large and al. (Large, 2014), our results suggest that VB is associated with SUD (Large et al., 2014), and that this co-morbidity should therefore be targeted for early screening and specific treatment (Langeveld et al., 2014; Large et al., 2014; Mullin et al., 2012). The same is true for impulsivity, which should be explored thoroughly considering it may be amenable to treatment and evolve positively. Exposure to trauma also seems to be a contributing factor in a certain number of patients. The impact of exposure to trauma during childhood on outcome has been clearly demonstrated in EPP, and research on offenders has shown that they are more likely to have experienced physical or psychological violence during childhood than the general population (Edwards, Holden, Felitti, \& Anda, 2003; Jespersen, Lalumière, \& Seto, 2009; McCormack, Hudson, \& Ward, 2002; Stirpe \& Stermac, 2003; Weeks \& Widom, 1998; Whitaker et al., 2008). The high occurrence of trauma in this population should encourage clinicians to explore this domain with caution and to take it into account when treating such patients, not only because of its impact on outcome, but also considering its impact on risk to display VB (Alameda et al., 2015; Conus, Cotton, Schimmelmann, McGorry, \& Lambert, 2010; Hoptman, 2015). 
A second subgroup of violent patients could be specific to EPP, in relation to lack of insight during this phase [at program entry : 47\% of VP had no insight and 30\% of NVP (Moulin et al., 2017)] and its consequence in social interactions. While the issue of insight should be approached carefully with EPP, attempts to promote its development should always be part of treatment and considered as a therapeutic process (Elowe \& Conus, 2017).

\section{LIMITATIONS}

Several limitations must be mentioned. First, assessment of impulsivity was based on 2 PANSS items rather than on a specifically designed scale. Second, assessment of positive symptoms should be more precise. Third, the four latent classes may reflect specificity of our sample and local characteristics and may not apply in other samples or settings. Our results must therefore be confirmed by other studies. Fourth, some VB may not have been reported to clinicians and researchers despite the three sources of information; in particular, VB occurring prior to entry into the program might have been underestimated, due to absence of access to criminal records. Fifth, a separate analysis of pre-treatment and in-program violence would be of interest, as well as separate analysis of serious and less serious violence. Given the limited sample size, these approaches were not feasible. Sixth, the diagnostic procedure focused mainly on the psychosis dimension and probably failed to provide reliable information regarding the presence of personality disorder comorbidity which is known to be a risk factor for VB. Finally, dynamic factors other than the ones we considered may also be linked to VB. 


\section{CONCLUSIONS}

Despite these limitations, our results revealed an important heterogeneity among EPP regarding rate of $\mathrm{VB}$, and suggest the possibility to identify subgroups of patient at higher risk to display $\mathrm{VB}$ on the basis of dynamic factors. This indicates in turn that preventive interventions may be developed and that they should mainly target SUD, impulsivity and insight. More research is warranted in this domain considering the relatively high prevalence of VB in this population and the devastating consequences they can have at various levels.

This article is protected by copyright. All rights reserved. 


\section{REFERENCES}

Aebi, M., Mohler-Kuo, M., Barra, S., Schnyder, U., Maier, T., \& Landolt, M. (2017). Posttraumatic stress and youth violence perpetration: a population-based cross-sectional study. European Psychiatry, 40, 88-95.

Alameda, L., Ferrari, C., Baumann, P., Gholam-Rezaee, M., Do, K., \& Conus, P. (2015). Childhood sexual and physical abuse: age at exposure modulates impact on functional outcome in early psychosis patients. Psychological Medicine, 1-10.

American Psychiatric Association. (2000). Diagnostic and Statistical Manual of Mental Disorders, $4^{\text {th }}$ edn. Washington, DC: American Psychiatric Association.

Baumann, P. S., Crespi, S., Marion-Veyron, R., Solida, A., Thonney, J., Favrod, J., . . . Conus, P. (2013). Treatment and Early Intervention in Psychosis Program (TIPP-Lausanne): implementation of an early intervention programme for psychosis in Switzerland. Early intervention in psychiatry, 7(3), 322-328.

Bjørkly, S. (2006). Empirical evidence of a relationship between insight and risk of violence in the mentally ill - a review of the literature. Aggression and violent Behavior, 11(4), 414-423.

Bjørkly, S. (2013). A systematic review of the relationship between impulsivity and violence in persons with psychosis: Evidence or spin cycle? Aggression and violent behavior, 18(6), 753-760.

Bo, S., Forth, A., Kongerslev, M., Haahr, U. H., Pedersen, L., \& Simonsen, E. (2013). Subtypes of aggression in patients with schizophrenia: The role of personality disorders. Criminal Behaviour and Mental Health, 23(2), 124-137.

Bonnet, S., Lacambre, M., Schandrin, A., Capdevielle, D., \& Courtet, P. (2017). Insight et dangerosité psychiatrique: revue de la littérature. L'Encéphale, 43(2), 146-153.

Coid, J. W., Ullrich, S., Kallis, C., Keers, R., Barker, D., Cowden, F., \& Stamps, R. (2013). The relationship between delusions and violence: findings from the East London first episode psychosis study. JAMA psychiatry, 70(5), 465-471.

Conus, P., \& Bonsack, C. (2004). Intervention précoce dans la phase initiale des troubles psychotiques à Lausanne: quels problèmes et quelles solutions?: La réhabilitation psychosociale des patients souffrant de troubles psychiques majeurs. Revue médicale de la Suisse romande, 124(4), 221-224.

Conus, P., Cotton, S., Schimmelmann, B. G., McGorry, P. D., \& Lambert, M. (2010). Pretreatment and outcome correlates of sexual and physical trauma in an epidemiological cohort of first-episode psychosis patients. Schizophrenia bulletin, 36(6), 1105-1114.

Douglas, K. S., Guy, L. S., \& Hart, S. D. (2009). Psychosis as a risk factor for violence to others: a metaanalysis. Psychological bulletin, 135(5), 679-706.

Douglas, K. S., \& Skeem, J. L. (2005). Violence risk assessment: getting specific about being dynamic. Psychology, Public Policy, and Law, 11(3), 347-383.

Drake, R. E., Osher, F. C., Noordsy, D. L., Hurlbut, S. C., Teague, G. B., \& Beaudett, M. S. (1990). Diagnosis of alcohol use disorders in schizophrenia. Schizophrenia Bulletin, 16(1), 57-67.

Dubreucq, J.-L., Joyal, C., \& Millaud, F. (2005). Risque de violence et troubles mentaux graves. Annales Médico-psychologiques, revue psychiatrique, 163(10), 852-865.

Dumais, A., Potvin, S., Joyal, C., Allaire, J.-F., Stip, E., Lesage, A., . . . Côté, G. (2011). Schizophrenia and serious violence: a clinical-profile analysis incorporating impulsivity and substance-use disorders. Schizophrenia research, 130(1), 234-237.

Edwards, V. J., Holden, G. W., Felitti, V. J., \& Anda, R. F. (2003). Relationship Between Multiple Forms of Childhood Maltreatment and Adult Mental Health in Community Respondents: Results From the Adverse Childhood Experiences Study. American Journal of Psychiatry, 160, 1453-1460.

Elbogen, E. B., \& Johnson, S. C. (2009). The intricate link between violence and mental disorder: results from the National Epidemiologic Survey on Alcohol and Related Conditions. Archives of general Psychiatry, $66(2), 152-161$.

Elowe, J., \& Conus, P. (2017). Much ado about everything: A literature review of insight in first episode psychosis and schizophrenia. European Psychiatry, 39, 73-79.

Enticott, P. G., Ogloff, J. R., \& Bradshaw, J. L. (2008). Response inhibition and impulsivity in schizophrenia. Psychiatry research, 157(1), 251-254.

Fazel, S., Långström, N., Hjern, A., Grann, M., \& Lichtenstein, P. (2009). Schizophrenia, substance abuse, and violent crime. JaMa, 301(19), 2016-2023. 
Foley, S. R., Kelly, B. D., Clarke, M., McTigue, O., Gervin, M., Kamali, M., . . Browne, S. (2005). Incidence and clinical correlates of aggression and violence at presentation in patients with first episode psychosis. Schizophrenia research, 72(2), 161-168.

Goldman, H. H., Skodol, A. E., \& Lave, T. R. (1992). Revising axis V for DSM-IV: a review of measures of social functioning. Am J Psychiatry, 149(9), 1148-1156.

Grann, M., Danesh, J., \& Fazel, S. (2008). The association between psychiatric diagnosis and violent reoffending in adult offenders in the community. BMC Psychiatry, 8(1), 1-7. doi:10.1186/1471-244x-892

Hodgins, S. (2008). Violent behaviour among people with schizophrenia: a framework for investigations of causes, and effective treatment, and prevention. Philosophical Transactions of the Royal Society B: Biological Sciences, 363(1503), 2505-2518.

Hodgins, S. (2010). Quelles sont les données de la littérature concernant la violence hétéro-aggressive chez les personnes ayant une psychopathie associée à une schizophrénie ou à un trouble de l'humeur. Audition publique. Paris HAS textes d'experts, 101-123.

Hodgins, S., Calem, M., Shimel, R., Williams, A., Harleston, D., Morgan, C., . . Lappin, J. (2011). Criminal offending and distinguishing features of offenders among persons experiencing a first episode of psychosis. Early intervention in psychiatry, 5(1), 15-23.

Hoptman, M. J. (2015). Impulsivity and aggression in schizophrenia: a neural circuitry perspective with implications for treatment. CNS spectrums, 20(03), 280-286.

Jespersen, A. F., Lalumière, M. L., \& Seto, M. C. (2009). Sexual abuse history among adult sex offenders and non-sex offenders: A meta-analysis. Child Abuse \& Neglect, 33(3), 179-192. doi:10.1016/j.chiabu.2008.07.004

Joyal, C. C., Côté, G., Meloche, J., \& Hodgins, S. (2011). Severe mental illness and aggressive behavior: on the importance of considering subgroups. International Journal of Forensic Mental Health, 10(2), 107-117.

Joyal, C. C., Dubreucq, J.-L., Gendron, C., \& Millaud, F. (2007). Major mental disorders and violence: a critical update. Current psychiatry reviews, 3(1), 33-50.

Joyal, C. C., Putkonen, A., Paavola, P., \& Tiihonen, J. (2004). Characteristics and circumstances of homicidal acts committed by offenders with schizophrenia. Psychological Medicine, 34(03), 433-442.

Kay, S. R., Flszbein, A., \& Opfer, L. A. (1987). The positive and negative syndrome scale (PANSS) for schizophrenia. Schizophrenia bulletin, 13(2), 261-276.

Langeveld, J., Bjørkly, S., Auestad, B., Barder, H., Evensen, J., ten Velden Hegelstad, W., . . Melle, I. (2014). Treatment and violent behavior in persons with first episode psychosis during a 10-year prospective follow-up study. Schizophrenia research, 156(2), 272-276.

Lapworth, K., Dawe, S., Davis, P., Kavanagh, D., Young, R., \& Saunders, J. (2009). Impulsivity and positive psychotic symptoms influence hostility in methamphetamine users. Addictive behaviors, 34(4), 380385.

Large, M. M. (2014). Treatment of psychosis and risk assessment for violence. American Journal of Psychiatry, $171(13), 256-258$.

Large, M. M., Dall, B., \& Nielssen, O. B. (2014). Risk assessment for violence and self-harm in first episode psychosis and the need for early psychosis intervention services. Australian and New Zealand journal of psychiatry, 48(1), 94-95.

Large, M. M., \& Nielssen, O. (2011). Violence in first-episode psychosis: a systematic review and metaanalysis. Schizophrenia research, 125(2), 209-220.

Latalova, K. (2014). Violence and duration of untreated psychosis in first-episode patients. International journal of clinical practice, 68(3), 330-335.

Lincoln, T. M., Lüllmann, E., \& Rief, W. (2007). Correlates and long-term consequences of poor insight in patients with schizophrenia. A systematic review. Schizophrenia bulletin, 33(6), 1324-1342.

McCormack, J., Hudson, S. M., \& Ward, T. (2002). Sexual offenders' perceptions of their early interpersonal relationships: an attachment perspective. The Journal of Sex Research, 39(2), 85-93.

Moeller, F. G., Barratt, E. S., Dougherty, D. M., Schmitz, J. M., \& Swann, A. C. (2001). Psychiatric aspects of impulsivity. American journal of psychiatry, 158(11), 1783-1793. 
Morosini, P., Magliano, L., Brambilla, L., Ugolini, S., \& Pioli, R. (2000). Development, reliability and acceptability of a new version of the DSM-IV Social and Occupational Functioning Assessment Scale (SOFAS) to assess routine social funtioning. Acta Psychiatrica Scandinavica, 101(4), 323-329.

Moulin, V., Golay, P., Azzola, A., Palix, J., Baumann, P., Do, K. Q., . . Conus, P. (Submitted). Impulsivity in early psychosis, a direct link with violent behaviour and a target for intervention.

Moulin, V., Palix, J., Alameda, L., Gholamrezaee, M.-M., Baumann, P. S., Gasser, J., . . . Conus, P. (2017). Insight and violent behavior in a cohort of early psychosis patients. The Canadian Journal of Psychiatry, in press, 1-10.

Mullin, K., Gupta, P., Compton, M. T., Nielssen, O., Harris, A., \& Large, M. (2012). Does giving up substance use work for patients with psychosis? A systematic meta-analysis. Australian and New Zealand Journal of Psychiatry, 46(9), 826-839.

Negrao, C., Bonanno, G. A., Noll, J. G., Putnam, F. W., \& Trickett, P. K. (2005). Shame, humiliation, and childhood sexual abuse : distinct contributions and emotional coherence. Child maltreatment, 10, 350363.

Nielssen, O. B., Malhi, G. S., McGorry, P. D., \& Large, M. M. (2012). Overview of violence to self and others during the first episode of psychosis. The Journal of clinical psychiatry, 73(5), e580-587.

Nijman, H. L., Muris, P., Merckelbach, H. L., Palmstierna, T., Wistedt, B., Vos, A., . . Allertz, W. (1999). The staff observation aggression scale-revised (SOAS-R). Aggressive behavior, 25(3), 197-209.

Nolan, K. A., Volavka, J., Czobor, P., Sheitman, B., Lindenmayer, J.-P., Citrome, L. L., . . Lieberman, J. A. (2005). Aggression and psychopathology in treatment-resistant inpatients with schizophrenia and schizoaffective disorder. Journal of psychiatric research, 39(1), 109-115.

Ouzir, M. (2013). Impulsivity in schizophrenia: a comprehensive update. Aggression and Violent Behavior, $18(2), 247-254$.

Putkonen, A., Kotilainen, I., Joyal, C. C., \& Tiihonen, J. (2004). Comorbid personality disorders and substance use disorders of mentally ill homicide offenders: A structured clinical study on dual and triple diagnoses. Schizophrenia Bulletin, 30(1), 59-72.

Reinharth, J., Reynolds, G., Dill, C., \& Serper, M. (2014). Cognitive predictors of violence in schizophrenia: a meta-analytic review. Schizophrenia Research: Cognition, 1(2), 101-111.

Schwarz, G. (1978). Estimating the dimension of a model. The annals of statistics, 6(2), 461-464.

Silverstein, S. M., Del Pozzo, J., Roché, M., Boyle, D., \& Miskimen, T. (2015). Schizophrenia and violence: realities and recommendations. Crime Psychology Review, 1(1), 21-42.

Stirpe, T. S., \& Stermac, L. E. (2003). An exploration of childhood victimization and family-of-origin characteristics of sexual offenders against children. International Journal of Offender therapy and Comparative Criminology, 47(5), 542-555.

Swanson, J. W., Swartz, M. S., Van Dorn, R. A., Elbogen, E. B., Wagner, H. R., Rosenheck, R. A., . . . Lieberman, J. A. (2006). A national study of violent behavior in persons with schizophrenia. Archives of general psychiatry, 63(5), 490-499.

Vacheron, M.-N., \& Cornic, F. (2010). Quels sont les facteurs généraux et spécifiques de violence? Dangerosité psychiatrique: étude et évaluation des facteurs de risque de violence hétéro-agressive chez les personnes ayant une schizophrénie ou des troubles de l'humeur, 135-186.

Varese, F., Smeets, F., Drukker, M., Lieverse, R., Lataster, T., Viechtbauer, W., . . . Bentall, R. P. (2012). Childhood adversities increase the risk of psychosis: a meta-analysis of patient-control, prospective-and cross-sectional cohort studies. Schizophrenia bulletin, sbs050.

Verma, S., Poon, L. Y., Subramaniam, M., \& Chong, S.-A. (2005). Aggression in Asian patients with firstepisode psychosis. International journal of social psychiatry, 51(4), 365-371.

Volavka, J., \& Citrome, L. (2008). Heterogeneity of violence in schizophrenia and implications for long-term treatment. International Journal of Clinical Practice, 62(8), 1237-1245. doi:10.1111/j.17421241.2008.01797.x

Voyer, M., Jaafari, N., \& Senon, J.-L. (2011). Insight et comportements violents chez les patients souffrant d'une schizophrénie. Annales Médico-psychologiques, revue psychiatrique, 169(7), 441-443.

Webster, C., Douglas, K., Eaves, D., \& Hart, S. (1997). HCR-20: Assessing Risk for Violence (Version 2). Burnaby, British Columbia, Canada, Simon Fraser University. Mental Health, Law, and Policy Institute. 
Weeks, R., \& Widom, C. S. (1998). Self-reports of early childhood victimization. Journal of Interpersonal Violence, 13, 346-361.

Whitaker, D. J., Le, B., Karl Hanson, R., Baker, C. K., McMahon, P. M., Ryan, G., . . Rice, D. D. (2008). Risk factors for the perpetration of child sexual abuse: A review and meta-analysis. Child Abuse \& Neglect, 32(5), 529-548. doi:10.1016/j.chiabu.2007.08.005

Winsper, C., Ganapathy, R., Marwaha, S., Large, M., Birchwood, M., \& Singh, S. P. (2013). A systematic review and meta-regression analysis of aggression during the First Episode of Psychosis. Acta Psychiatrica Scandinavica, 128(6), 413-421.

Witt, K., Lichtenstein, P., \& Fazel, S. (2015). Improving risk assessment in schizophrenia: epidemiological investigation of criminal history factors. The British Journal of Psychiatry, 206(5), 424-430.

Witt, K., Van Dorn, R., \& Fazel, S. (2013). Risk factors for violence in psychosis: systematic review and metaregression analysis of 110 studies. PloS one, 8(2), e55942.

Yung, A. R., Yung, A. R., Pan Yuen, H., Mcgorry, P. D., Phillips, L. J., Kelly, D., . . Killackey, E. (2005). Mapping the onset of psychosis: the comprehensive assessment of at-risk mental states. Australian and New Zealand journal of psychiatry, 39(11-12), 964-971.

\section{Contributors}

VM and PC wrote the manuscript with contributions from all authors. LA enrolled patients in the study, MG and PG performed the statistical analyses. All authors contributed to and have approved the final manuscript.

\section{Conflict of interest}

No conflicts of interest to declare. 


\section{University Library}

\section{- M M N E R VA A gateway to Melbourne's research publications}

Minerva Access is the Institutional Repository of The University of Melbourne

Author/s:

Moulin, V;Palix, J;Golay, P;Dumais, A;Gholamrezaee, MM;Azzola, A;Baunnann, PS;Alanneda, L;Conus, P

Title:

Violent behaviour in early psychosis patients: Can we identify clinical risk profiles?

Date:

2019-06-01

\section{Citation:}

Moulin, V., Palix, J., Golay, P., Dumais, A., Gholamrezaee, M. M., Azzola, A., Baunnann, P. S., Alanneda, L. \& Conus, P. (2019). Violent behaviour in early psychosis patients: Can we identify clinical risk profiles?. EARLY INTERVENTION IN PSYCHIATRY, 13 (3), pp.517-524. https://doi.org/10.1111/eip.12512.

Persistent Link:

http://hdl.handle.net/11343/293864 